\title{
Pharmacovigilance in palliative care
}

\section{Debra Rowett \\ Service director \\ Drug and Therapeutics \\ Information Service \\ Repatriation General \\ Hospital \\ David Currow \\ Professor \\ Discipline of Palliative and \\ Supportive Services \\ Flinders University \\ Adelaide}

\section{Key words}

adverse effects, opioids

\section{Aust Prescr 2014;37:204-9}

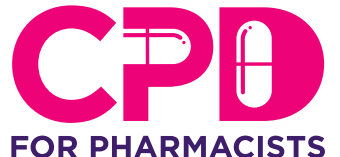

FOR PHARMACISTS

This article has a continuing professional development activity for pharmacists available at

www.australianprescriber.com/ continuing-professionaldevelopment

\section{SUMMARY}

Patients receiving palliative care are at high risk of adverse effects from drugs. As these effects can be difficult to distinguish from the symptoms of the terminal illness, harm from medicines is often not recognised.

Adverse effects can contribute to the burden of symptoms, at a time when good control of symptoms is paramount. Adding another drug to treat the adverse effects can compound the problem.

Patients should be asked about their symptoms as they may not volunteer the information or recognise the link with their medicines. Reviewing their treatment may prompt a change in dose, drug or lead to some treatments being stopped.

\section{Introduction}

In Australia over 140000 people die each year including 100000 whose deaths are expected because of a terminal condition., ${ }^{1,2}$ The increasing number of deaths related to organ failure and physical and cognitive frailty mean that many patients now have longer periods between diagnosis and death. A prolonged deteriorating phase will therefore require longer periods of drug therapy to reduce symptoms.

Prescribing medicines to relieve suffering and distress is a cornerstone of palliative care. However, there is limited evidence about the efficacy and safety of many drugs in palliative care. Currently most of this evidence comes from patients with cancer rather than those with other terminal chronic diseases.

Palliative care requires the balancing of many considerations, including a judicious appraisal of the benefits and harms of both pharmacological and nonpharmacological treatments. Pharmacovigilance, the process of monitoring, evaluating and improving the safety of medicines, is essential if palliative care is to maximise the benefits from medicines and minimise the harms. Pharmacovigilance data have not been systematically collected in palliative care.

\section{Balancing harm and benefit}

Palliative care is not just about the last days of life. It now includes care for weeks, months, and for some people, years reflecting the different disease trajectories for cancer, organ failure and dementia. The balance between the benefit and harm of drugs will fluctuate depending on whether the patient's condition is stable, unstable, deteriorating or terminal. ${ }^{3}$ The patient's needs and choices will also change as the disease progresses.
Little is known about the prevalence of adverse drug events in palliative care. These patients have a high risk of adverse events because they are often elderly with multiple concomitant drug therapies, both for symptom control and for management of the terminal disease and other chronic conditions. They may experience significant weight loss, diminished oral intake, and altered organ function each of which can change a drug's pharmacokinetics and pharmacodynamics. The burden of advancing disease and multiple morbidities often results in progressive increases in the number of drugs prescribed. ${ }^{4}$ Many patients will also be using nonprescribed treatments, including over-the-counter and complementary medicines, increasing the risk of interactions.

The adverse effects of drugs may have significant functional consequences for patients and their families. There are also associated burdens for patients, carers and families in managing the cost and complexity of medication regimens.

Balancing benefit and harm becomes increasingly challenging because of the difficulty in differentiating the pathology of the underlying progressive, lifelimiting illness from emerging and fluctuating adverse drug effects. Symptoms may easily be misattributed because clinicians, patients and their families know that dying often brings with it a collection of worsening symptoms.

\section{Decision making}

Information from the patient, their families and carers about their goals and values is vital for informing decisions about treatment. ${ }^{5}$

Adverse effects may be weighed differently by patients and their families. Patients may have a 
strong preference for having an opportunity to gain a sense of completion in their lives, of being able to say goodbye, resolve unfinished business and complete last tasks. ${ }^{6}$ While good pain control is essential, in one study physicians considered mental awareness to be much less important than pain control in contrast with patients who strongly valued being mentally aware. This study suggests that patients may be less willing to sacrifice lucidity for analgesia than doctors think. ${ }^{6}$

Treatments should be altered as symptoms change with time, reflecting changes in the patient's condition. The expected benefits may diminish and the likely harms increase so the original therapeutic goals will need to be reset. ${ }^{?}$

Chronic diseases should be managed differently in patients who have little life remaining. The number needed to treat for one patient to benefit will tend to increase as death approaches because of the shortened prognosis, and the number needed to harm will fall as adverse effects become more frequent. The focus of prescribing should be on improving the quality of life while preventing avoidable harms. ${ }^{4,8}$ For example, there is little point in continuing a lipidlowering drug in someone who is dying.

\section{Symptom cascades}

Drugs play an important role in relieving common symptoms, but there is a need to be vigilant for the 'symptom cascades' that result from adverse effects.

Some of these symptom cascades are expected, such as constipation in patients starting opioids. Other examples of symptoms resulting from adverse effects are shown in Table $1 .{ }^{9}$

\section{Common symptoms}

There can be a tenfold difference between the number of symptoms volunteered by patients and those identified using systematic assessment. ${ }^{10} \mathrm{~A}$ study revealed that $69 \%$ of severe symptoms and $79 \%$ of distressing symptoms were not volunteered. This makes it difficult to identify symptoms that may be drugrelated or exacerbated by drugs. Symptom assessment by nurses or other proxies only modestly correlates with the patient's assessment and can significantly under-represent the patient's actual symptom burden."

Drugs may be either the primary cause, or exacerbate an underlying cause, of many common symptoms. Medicines that are used to treat a particular symptom may also cause that symptom, for example antipsychotics and benzodiazepines can trigger delirium. ${ }^{9}$

\section{Table 1 Common drug-related symptoms in palliative care ${ }^{9}$}

\begin{tabular}{|c|c|}
\hline Symptom & Drugs which may cause, contribute to or exacerbate these symptoms \\
\hline fatigue & chemotherapy, opioids (chronic), anticonvulsants (carbamazepine, gabapentin) \\
\hline anxiety & corticosteroids, withdrawal of benzodiazepines, opioids or antidepressants \\
\hline dry mouth & $\begin{array}{l}\text { opioids, anticholinergics, antidepressants, antipsychotics, antihistamines, benzodiazepines, diuretics, anticonvulsants } \\
\text { (carbamazepine, pregabalin, gabapentin), proton pump inhibitors }\end{array}$ \\
\hline depression & corticosteroids \\
\hline hiccups & corticosteroids (dexamethasone), benzodiazepines, antipsychotics \\
\hline delirium & opioids, benzodiazepines, antipsychotics, anticonvulsants, anticholinergics, corticosteroids \\
\hline insomnia & corticosteroids \\
\hline constipation & $\begin{array}{l}\text { opioids, tricyclic antidepressants, anticholinergics, anticonvulsants (pregabalin), antipsychotics, benzodiazepines, diuretics, iron, } \\
\text { calcium channel blockers (verapamil, diltiazem), antacids containing calcium and aluminium, calcium supplements, } 5 \mathrm{HT}_{3} \text { receptor } \\
\text { antagonists (ondansetron, granisetron, dolasetron) }\end{array}$ \\
\hline drowsiness & opioids, antipsychotics, anticonvulsants, anticholinergics, benzodiazepines \\
\hline restlessness & metoclopramide, antipsychotics, opioids \\
\hline diarrhoea & laxatives, cholinesterase inhibitors, antibiotics, chemotherapy \\
\hline sweating & antidepressants, cholinesterase inhibitors, opioids, sialogogues (pilocarpine), tramadol \\
\hline nausea & $\begin{array}{l}\text { opioids, anticonvulsants, antibiotics, antidepressants, antipsychotics, corticosteroids, non-steroidal anti-inflammatory drugs, } \\
\text { tramadol, chemotherapy }\end{array}$ \\
\hline vomiting & opioids, chemotherapy, anticonvulsants (carbamazepine, sodium valproate, phenytoin), antibiotics, antifungals \\
\hline
\end{tabular}


Drug-induced symptoms are usually a diagnosis of exclusion of other causes, but this is not always possible in palliative care. Some symptoms are also discontinuation effects when a drug is not taken, such as when agitation results from missed antidepressant doses.

\section{Delirium}

Delirium is a common neuropsychiatric complication in palliative care. It can result from a combination of predisposing baseline risk factors and superimposed precipitating factors. ${ }^{12}$ The prevalence is $26-62 \%$ for palliative care inpatients and up to $88 \%$ in the last days and hours of life. ${ }^{12}$

Many drugs used for symptom control in palliative care (for example, benzodiazepines, corticosteroids, anticholinergics, opioids, antipsychotics) can exacerbate or cause neuropsychiatric adverse effects, including delirium. Opioids can cause delirium, but so can uncontrolled pain.

There are many similarities between the clinical presentation observed in terminal restlessness and delirium. This has led to the suggestion that terminal restlessness may actually be a potentially reversible acute delirium. ${ }^{13} \mathrm{~A}$ study of the occurrence, precipitating factors, and reversibility of delirium in patients with advanced cancer found that it was reversible in $49 \%$ of episodes. ${ }^{14}$

\section{Management options}

An individualised approach is required which takes account of the level of investigation needed to identify reversible causes and the intensity of the therapeutic intervention to control delirium.

Initial management includes the identification of reversible causes. Many cases can be reversed if the delirium was precipitated by drugs, electrolyte abnormalities (which may also be drug induced) or infection. ${ }^{12}$ Non-drug strategies such as maintaining calm and quiet surroundings may be appropriate in some circumstances. Antipsychotics, specifically haloperidol, are widely used although there is limited evidence in palliative care. Benzodiazepines lack evidence to support their use for delirium in palliative care. Importantly, both antipsychotics and benzodiazepines can also cause delirium.

\section{Constipation}

Altered bowel habit is very common during palliative care. There are likely to be numerous concurrent risk factors, but opioids are often responsible. The relative contribution of different factors will change over time and it is often difficult to attribute constipation to opioids alone. For example, the catabolic state of cachexia, decreasing mobility and oral intake, and drugs with anticholinergic adverse effects are all likely to contribute..$^{15}$ Opioids and other drugs may simply 'tip the balance'.

Observational studies report that up to $60 \%$ of patients admitted to palliative care units are already receiving laxatives with the majority taking more than one type of laxative. ${ }^{16}$ However, constipation is still often underdiagnosed and undertreated in palliative care. ${ }^{17}$

The consequences of constipation (see Box) ${ }^{18}$ can contribute significantly to the patient's symptom burden. This may result in prescribing cascades to treat the complications, with further potential for drug-related adverse effects. This includes the potential for harm from laxatives, such as the salt and water retention associated with some macrogol formulations which have a high sodium content, or pain associated with stimulant laxatives in people who have hard or impacted stools. Bowel perforation is a rare but important severe adverse effect.

\section{Management options}

In addition to addressing and modifying reversible causes of constipation, including drugs, laxatives are usually required. Current clinical guidelines such as Therapeutic Guidelines: Palliative Care ${ }^{19}$ recommends that, if it is safe to do so, the initial prescription should be an oral stool softener and a stimulant laxative. Rectal interventions may also be necessary when impaction has occurred, particularly if myopathy or neuropathy is contributing to the problem. After excluding bowel obstruction, methylnaltrexone can be tried in opioid-induced constipation which has failed to respond to laxatives.

\section{Box Potential consequences of drug-induced constipation}

\section{Gastrointestinal}

Impaction, obstruction, megacolon, faecal incontinence, rectal prolapse, haemorrhoids, bloating, anorexia and vomiting

\section{Cardiac and vascular}

Arrhythmias, vasovagal episodes, angina

\section{Urological}

Retention, incontinence, urinary infection

\section{Other}

Delirium, anxiety, analgesic failure (opioid dose-limiting constipation), worsening pain, impaired quality of life

Adapted from reference 18 


\section{Urinary symptoms}

Many medicines can contribute to urinary symptoms (see Table 2). ${ }^{20-22}$ Anticholinergic effects contribute to and worsen urinary symptoms particularly urinary retention and overflow incontinence. Complementary medicines can also cause problems. For example, St John's wort has been associated with voiding difficulty, and guarana or large amounts of caffeine can increase diuresis, aggravate detrusor instability and worsen urge incontinence.

Many patients experience urinary symptoms, but often do not disclose them. If they are not asked directly, urinary incontinence may go unrecognised by clinicians. The causes are likely to be multifactorial and fluctuate so the contribution to symptom burden will vary. Urinary incontinence and faecal incontinence can sometimes be the 'last straw' for managing a person at home.

Urinary incontinence can impair participation in daily activities, physical functioning, psychological wellbeing, and overall quality of life. Patients with urge incontinence are almost twice as likely to fall than other patients. ${ }^{23}$ Incontinence can also put patients at increased risk of skin and urinary tract infections. Drug-related urinary retention is potentially reversible. Agitation and restlessness may be the result of a full

\section{Table 2 Drugs that can cause or exacerbate urinary incontinence $20-22$}

\begin{tabular}{|c|c|c|}
\hline Drug & Effect & $\begin{array}{l}\text { Type of incontinence } \\
\text { caused }\end{array}$ \\
\hline ACE inhibitors & cough & stress \\
\hline Diuretics & diuresis (polyuria) & urge \\
\hline Verapamil & $\begin{array}{l}\text { impaired emptying (retention), voiding difficulty, constipation, dependent oedema } \\
\text { (nocturnal polyuria) }\end{array}$ & overflow, urge \\
\hline $\begin{array}{l}\text { Alpha adrenergic agonists } \\
\text { (pseudoephedrine) }\end{array}$ & increase urethral and prostate capsule smooth muscle tone (obstruction and retention) & overflow \\
\hline $\begin{array}{l}\text { Alpha adrenergic antagonists } \\
\text { (prazosin, tamsulosin, terazosin) }\end{array}$ & sphincter relaxation & stress \\
\hline $\begin{array}{l}\text { Anticholinergics (oxybutynin, } \\
\text { solifenacin, tolterodine) }\end{array}$ & $\begin{array}{l}\text { reduce detrusor activity (retention), bladder outlet obstruction, constipation, } \\
\text { sedation, dry mouth (polydipsia), blurred vision, confusion, delirium }\end{array}$ & $\begin{array}{l}\text { overflow, functional, } \\
\text { urge }\end{array}$ \\
\hline \multicolumn{3}{|l|}{ Some antihistamines, tiotropium } \\
\hline \multicolumn{3}{|l|}{ Antidepressants } \\
\hline selective serotonin reuptake inhibitors & increase detrusor activity, sedation & urge, functional \\
\hline tricyclic antidepressants & anticholinergic effect, sedation, confusion & overflow, functional \\
\hline Antipsychotics & $\begin{array}{l}\text { anticholinergic effect, sedation, confusion, impaired mobility, parkinsonism, } \\
\text { constipation }\end{array}$ & $\begin{array}{l}\text { overflow, functional, } \\
\text { stress }\end{array}$ \\
\hline Benzodiazepines & sedation, confusion, impaired mobility & functional \\
\hline $\begin{array}{l}\text { Opioids (oxycodone, morphine, fentanyl, } \\
\text { codeine, tramadol) }\end{array}$ & $\begin{array}{l}\text { impair voiding reflex (retention), reduce detrusor activity, constipation, sedation, } \\
\text { confusion }\end{array}$ & overflow, functional \\
\hline Alcohol & diuresis (polyuria), lowers central inhibition & urge, functional \\
\hline Caffeine & diuresis (polyuria) & urge \\
\hline Beta agonists & impair emptying (retention) & overflow \\
\hline $\begin{array}{l}\text { Cholinergics (donepezil, galantamine, } \\
\text { rivastigmine, bethanecol) }\end{array}$ & increase detrusor activity & urge \\
\hline Gabapentin & dependent oedema (nocturnal polyuria) & urge \\
\hline Rosiglitazone, pioglitazone & dependent oedema (nocturnal polyuria) & urge \\
\hline Lithium & polydipsia (polyuria) & urge \\
\hline Non-steroidal anti-inflammatory drugs & dependent oedema (nocturnal polyuria) & urge \\
\hline
\end{tabular}


and distended bladder and resolution of the problem can bring much relief.

\section{Management options}

Management of incontinence and urinary retention includes assessment of underlying causes. It may not be possible to change or alter effective drugs, for example analgesics, but careful review may identify drugs which are exacerbating incontinence and contributing to symptom burden. Some can be stopped or have their adverse effects managed, for example improved management of constipation may relieve urinary retention. A trial of simple catheterisation, repeated if necessary or leading to a permanent indwelling catheter, may be appropriate depending on the underlying aetiology of the urinary symptoms. ${ }^{19}$

\section{Dry mouth}

A dry mouth may be caused by underlying disease, surgery, radiotherapy, fluid restriction and many drugs. It is a common symptom, but patients do not often complain about it. A study of 200 patients revealed that dry mouth was only volunteered by $1.5 \%$ of them, however when systematically assessed $65.5 \%$ had the symptom. ${ }^{10}$ It can result in a very painful, sore mouth which impacts on the ability to eat, drink, take medicines or talk.

A hospice study found that dry mouth can contribute to the risk of falls as patients may struggle to get water to quench their thirst, particularly marginally ambulant patients who feel uneasy about asking for help or losing independence. ${ }^{24}$

Commonly used medicines for symptoms such as pain, nausea, agitation, delirium and confusion may contribute to dry mouth. Many medicines for comorbid conditions also contribute to a cumulative anticholinergic burden. ${ }^{25,26}$

Fluid intake for some patients needs to be carefully balanced, for example in heart failure, while for others increasing fluid intake to relieve dry mouth can contribute to increased urinary frequency. Moving more frequently to the toilet may exacerbate painful movements and trigger other symptom cascades for which additional drugs may be prescribed. If movement is not possible, additional toileting can increase the burden on patients and carers. ${ }^{27}$

\section{Management options}

Carmellose spray and hypromellose gel for dry mouth and benzydamine for painful mouth are available through the palliative care section of the Pharmaceutical Benefits Scheme. ${ }^{28} \mathrm{~A}$ few treatment options advocated for dry mouth can worsen or exacerbate painful mouths in some people, for example lemon and glycerine mouth swabs. It is important to individualise treatment and monitor outcomes to enable timely changes in management.

\section{Pharmacovigilance and research}

There are very few studies of adverse drug events in palliative care. ${ }^{29}$ In addition, the impact of adverse effects, such as urinary and faecal incontinence, anorexia, confusion, restlessness and agitation, on patients and their carers has not been well studied.

There is a need to be aware that drugs may contribute to symptom clusters or cascades in palliative care. Identifying an adverse drug event presents an opportunity to effect a 'cure' by lowering the dose, stopping the drug or changing to a less 'toxic' treatment. ${ }^{30}$ Stopping treatment is an integral part of good prescribing and should be reflected in conversations with the patients and their carers.

The discipline of palliative care aims to improve its evidence base for clinical prescribing. In Australia randomised controlled trials of drugs in palliative care are being conducted as part of the Palliative Care Clinical Studies Collaborative (PaCCSC). ${ }^{28,31,32}$ A need to encourage the reporting of adverse drug events has prompted the development of the PaCCSC Rapid Pharmacovigilance studies, with more than 90 centres in 18 countries now participating. ${ }^{33}$ Adverse events should be reported to the Office of Product Review of the Therapeutic Goods Administration.

\section{Conclusion}

The increasing use of drugs for chronic disease and symptom management in palliative care increases the risk of adverse effects. There is a need to review the patient's symptoms to see if they are caused or exacerbated by drugs. Unnecessary medicines should be stopped safely and non-pharmacological options should be considered.

As patients often do not volunteer their symptoms, ask about problems which may be adverse effects of treatment. Pharmacovigilance does not end when palliative care begins. $<$

Conflict of interest: none declared 


\section{REFERENCES}

The full list of references and further reading is published with the online version of this article at www.australianprescriber.com/magazine/37/6/204/9

4. Currow DC, Stevenson JP, Abernethy AP, Plummer J, Shelby-James TM. Prescribing in palliative care as death approaches. J Am Geriatr Soc 2007;55:590-5.

6. Steinhauser KE, Christakis NA, Clipp EC, McNeilly M, Mclntyre L, Tulsky JA. Factors considered important at the end of life by patients, family, physicians, and other care providers. JAMA 2000;284:2476-82.

7. Stevenson J, Abernethy AP, Miller C, Currow DC. Managing comorbidities in patients at the end of life. BM 2004;329:909-12

8. Holmes HM. Rational prescribing for patients with a reduced life expectancy. Clin Pharmacol Ther 2009;85:103-7.

10. Homsi J, Walsh D, Rivera N, Rybicki LA, Nelson KA, Legrand SB, et al. Symptom evaluation in palliative medicine: patient report vs systematic assessment. Support Care Cancer 2006;14:444-53.
12. Bush SH, Kanji S, Pereira JL, Davis DH, Currow DC Meagher Dj, et al. Treating an established episode of delirium in palliative care: expert opinion and review of the current evidence base with recommendations for future development. J Pain Symptom Manage 2014;48:231-48.

13. White C, McCann MA, Jackson N. First do no harm... Terminal restlessness or drug-induced delirium. J Palliat Med 2007;10:345-51.

29. Currow DC, Rowett D, Doogue M, To TH, Abernethy AP. An international initiative to create a collaborative for pharmacovigilance in hospice and palliative care clinical practice. J Palliat Med 2012;15:282-6.

\section{Dental note}

\section{Managing the adverse effects of drugs used in palliative care}

Very few patients actually complain of oral dryness (1.5\%), yet on questioning, this is the second highest reported symptom of concern $(67 \%)$ in patients receiving palliative care. ${ }^{1} \mathrm{~A}$ study assessing end-of-life care found that of the 96 patients with an estimated life expectancy under three months, mouth pain was reported by $67 \%$, problems with food intake by $56 \%$, and dry mouth by $78 \%{ }^{2}$ What is disappointing is that $78 \%$ of these patients said that they had received no information about oral adverse effects of cancer treatment. ${ }^{2}$

In an interview-focused study of 14 palliative care patients, from a mid-sized hospital in regional Australia, it was found that a range of oral problems significantly impacted on their physical, social and psychological well-being to varying degrees, sometimes over extended periods of time. ${ }^{3}$ The participants reported a lack of oral assessment and virtually no input from dental experts to assist with palliating oral problems. ${ }^{3}$ These problems are not new. In the 1990s many terminally ill patients were found to have oral problems resulting from therapy and poor oral care during lengthy illnesses. It was suggested that by including a dentist in the palliative care team, the dental needs of dying patients would be likely to be managed more effectively. ${ }^{4}$

Dental assessments may well identify dental disease, to not only reduce the microbial load, but also decrease the risk of oral pain and infection. ${ }^{5}$ Including a dentist in the multidisciplinary approach to palliative care may also improve the patient's ability to speak, eat or swallow. ${ }^{5}$

Unfortunately, there is no single panacea for oral palliative care. There have been many suggested strategies, based on the limited clinical trial data available. ${ }^{6}$ Simple mouthwashes using bicarbonate ${ }^{7}$ may well be as effective as complex, over-thecounter and expensive topical products. These simple mouthwashes will not alleviate pain from dental disease, such as oral candidiasis, periodontal disease, tooth pain or abscesses, however dentists are excellent at dealing with specific physical curative treatment, that often has almost instantaneous results. Examples are the repair of a fractured tooth, the removal of an infected tooth, or the perfection of a smile with dental aesthetics.

\section{REFERENCES}

1. Homsi J, Walsh D, Rivera N, Rybicki LA, Nelson KA Legrand SB, et al. Symptom evaluation in palliative medicine: patient report vs systematic assessment.

Support Care Cancer 2006;14:444-53.

2. Wilberg P, Hjermstad MJ, Ottesen S, Herlofson BB. Oral health is an important issue in end-of-life cancer care. Support Care Cancer 2012;20:3115-22.

3. Rohr Y, Adams J, Young L. Oral discomfort in palliative care: results of an exploratory study of the experiences of terminally ill patients. Int J Palliat Nurs 2010;16:439-44.
4. Lapeer GL. The dentist as a member of the palliative care team. J Can Dent Assoc 1990;56:205-7.

5. Paunovich ED, Aubertin MA, Saunders MJ, Prange M. The role of dentistry in palliative care of the head and neck cancer patient. Tex Dent J 2000;117:36-45.

6. Sweeney MP, Bagg J. The mouth and palliative care. Am J Hosp Palliat Care 2000;17:118-24.

7. Oral and Dental Expert Group. Therapeutic Guidelines: Oral and dental. Version 2. Melbourne: Therapeutic Guidelines Limited; 2012.

\section{Michael McCullough}

On behalf of the Dental Therapeutics Committee Australian Dental

Association 